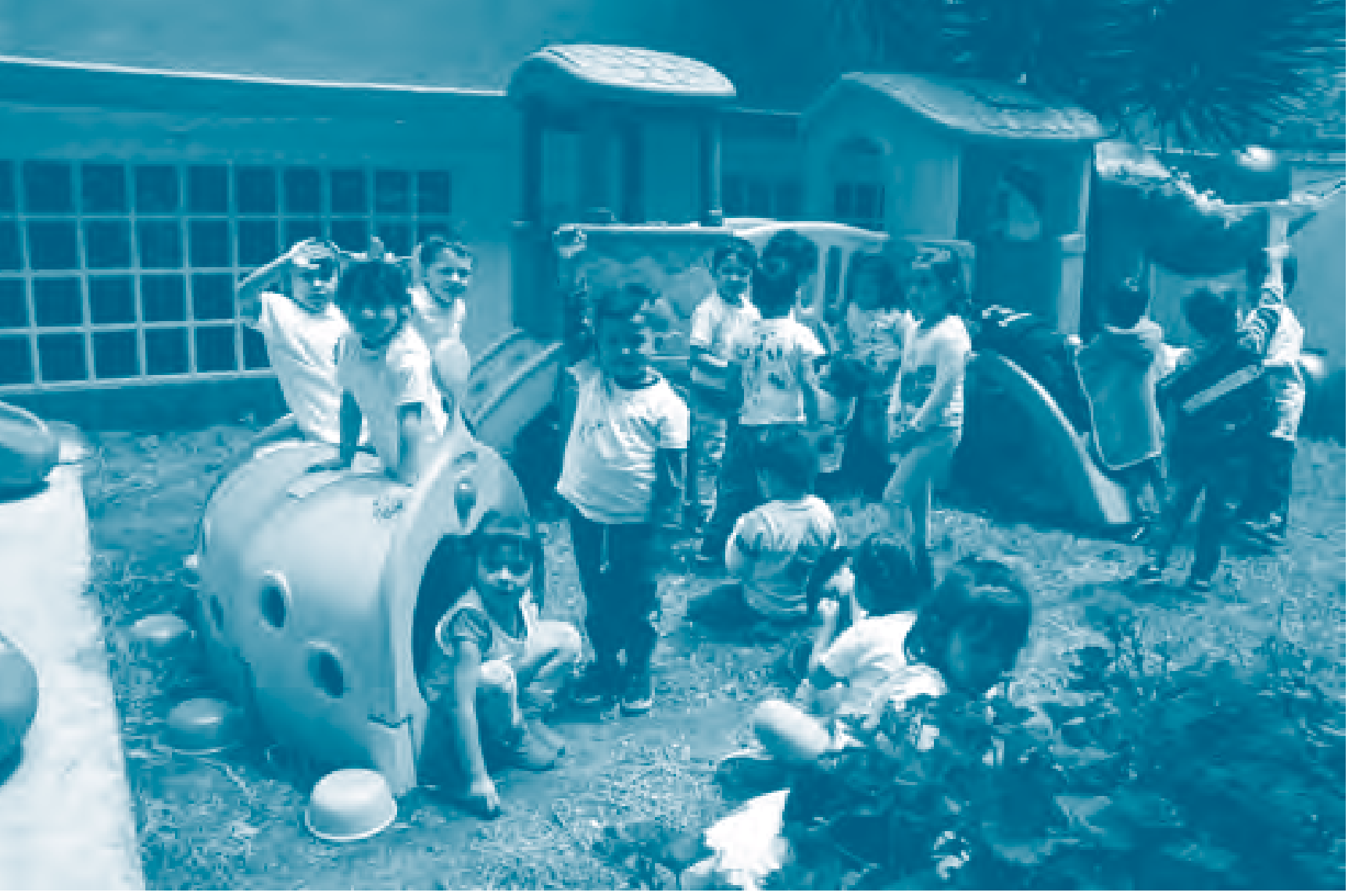

Capítulo 4.

Políticas públicas para la atención de la primera infancia afectada por el conflicto colombiano 
$\mathrm{E}$ ste capítulo tiene por objeto la reflexión sobre la atención que se brinda a la primera infancia desde las políticas públicas, en el marco de un sistema competente, especialmente la atención que se realiza con los menores de 5 años que han sido afectados directa o indirectamente por el conflicto colombiano. El capítulo inicia con una presentación de conceptos centrales sobre política pública y políticas públicas para la primera infancia en Colombia, para luego centrarse en los elementos de política pública, que a criterio de quienes participaron en la investigación, resultan necesarios para garantizar una adecuada atención a la primera infancia, tales como la integralidad, los sistemas de información, el monitoreo, la planeación y el presupuesto, todos ellos vitales para la competencia del sistema en sus diferentes niveles. Esto se hace partiendo del diálogo entre estos conceptos y los hallazgos encontrados en los participantes del estudio.

\section{Sobre el concepto de política pública}

Un país se desarrolla en la medida en que utiliza las herramientas necesarias para detectar cuáles son las principales problemáticas que le están aquejando en un momento determinado y brinda alternativas de solución, estratégicas y sostenibles, con el fin de dar manejo a dichas problemáticas.

Para Aguilar (2006), la tendencia mundial es que se pueda restablecer la naturaleza pública y asegurar un gobierno de calidad institucional, informativa y analítica -que tome decisiones con base en hechos fuertes y estudios rigurosos- y un gobierno de calidad gerencial, capaz de llevar a la práctica las decisiones que ha tomado. El tema hoy en el mundo es la calidad y no solamente el número de acciones del Estado. Cuando menciona restablecer la naturaleza pública, Aguilar (2006) hace referencia a que la actuación gubernamental sea legal y busque el beneficio público. Para este autor es necesario restablecer la deliberación y la corresponsabilidad ciudadana en los asuntos públicos, buscando su aporte para la identificación de los problemas sociales, la forma de abordarlos y la identificación de alternativas para cualificar las acciones institucionales, sociales e individuales que se requieren.

Con la promulgación de la Constitución Política en 1991 y la denominación Estado Social de Derecho, devienen para Colombia debates políticos, técnicos y académicos sobre los derechos humanos y los roles y responsabilidades del Estado, la sociedad y la familia en su garantía. Esto, sumado a los múltiples pactos que fueron adoptados en dicha década, como la Convención de los Derechos del Niño, favorecen que la infancia emerja como grupo poblacional relevante, que amerita una legislación y políticas particulares, acordes con las problemáticas y realidades que viven niños y niñas en el país.

Ahora bien, un tema se convierte en asunto de política pública cuando diversos actores construyen una visión compartida de reconocimiento del problema y este es incorporado a la agenda política. Para que un problema, entre tantos que existen en una sociedad, sea considerado materia de política pública, debe ser construido como 
cuestión pública, es decir, transformarse en un problema público. En efecto, las políticas públicas engloban el conjunto de procesos mediante los cuales las demandas sociales se transforman en opciones políticas y en decisiones públicas, gracias a la acción combinada de organizaciones, individuos situados estratégicamente y grupos que creen que pueden y debe hacerse algo y están en condiciones de promover la incorporación de su demanda en la agenda pública de problemas socialmente vigentes (Suárez, 1989). Así pues, podemos decir que la política pública es una herramienta que permite intervenir problemáticas sociales que afectan el bienestar de grupos sociales particulares.

Para facilitar la comprensión de las políticas públicas, autores como Meny y Thoenig (1992) propusieron el modelo del ciclo de política pública, en el que se presentan las políticas como fases secuenciales y ordenadas, tal como desde una mirada racional se esperaría que ocurriera. Desde este modelo se esperaría, entonces, que una vez se identifica una problemática social -ojalá relevante-, se procede con decidir las mejores opciones para resolverla, decisiones sobre las que se diseñan planes, programas y proyectos que puedan implementarse con esquemas de monitoreo y evaluación con el fin de contar con información que favorezca la solución de las problemáticas y la cualificación de la acción pública. Si bien es un modelo tentador para los diseñadores de política, y aún más para analistas, no es cierto que así suceda realmente, pues en cada una de las fases -que no se dan de manera ordenada y secuencial- existen tensiones, conflictos, confrontaciones de intereses e interpretaciones y disputas de recursos que ameritan lecturas amplias, complejas y demandantes por parte de los actores desde los diferentes niveles de planeación e implementación. A pesar de la advertencia anterior, resulta bastante útil usar las fases de ciclo analíticamente y comprender lo que sucede con determinadas problemáticas sociales asociadas a momentos determinados de una política.

Partiendo de lo anterior, uno de los aspectos más importantes del ciclo es la definición del problema. Los problemas de política no están dados, se construyen, hay que señalar los componentes cruciales del problema desde lógicas particulares, determinar hipótesis sobre sus causas y consecuencias y los aspectos sobre los que se deben centrar las acciones de Estado para su solución. Así, la construcción de un problema apuesta por una solución para entrar en una arena en la que se juegan otras posibles lecturas del problema y las maneras de tramitarlo.

Aguilar (2012) plantea que la política pública tiene dimensiones: una jurídica, que debe asegurar su legalidad mediante la compatibilidad con la Constitución Política y el cuerpo legislativo vigente; una segunda dimensión, que hace referencia a la economía, pues indica que la política pública debe respetar una racionalidad económica y finos análisis y cálculos de costo-eficacia de los recursos públicos; una dimensión organizacional, en la que es necesario identificar o desarrollar organizaciones gubernamentales, no gubernamentales o comunitarias para operativizar las acciones propuestas, y para esto es necesario conocer y contar con las estructuras y siste- 
mas que existen, su normatividad, distribución de la autoridad, división del trabajo, equipamiento tecnológico, cultura organizacional y sentido de la responsabilidad; de allí que sea fundamental analizar la estructura del Estado y la capacidad de sus organizaciones para asegurar el logro de la política. Y, por último, está la dimensión política, que hace referencia a que para evitar que una política sea automáticamente rechazada deber ser susceptible de obtener consenso, confianza y apoyo social.

Ahora bien, y ¿por qué los niños, niñas y adolescentes son políticamente prioritarios? El Departamento Nacional de Planeación, Ministerio de Educación Nacional, Ministerio de Protección Social e Instituto Colombiano de Bienestar Familiar (2007), indican que hasta hace poco los niños no eran sujetos de política, sino objetos de asistencia social. Darle la prioridad política que requiere la infancia se ha ido ganando con el tiempo con base en tres justificaciones: 1) ética, ya que el desarrollo y la protección de los niños nos dignifica como sociedad y garantiza nuestro desarrollo actual y futuro; 2) jurídica, dados los compromisos legales adquiridos en torno a la garantía de derechos de los niños y niñas y 3) política, ya que la acción del Estado se hace más efectiva, porque las inversiones con esta población son más benéficas para sentar bases de desarrollo y cambio social.

\section{Las políticas públicas para primera infancia en Colombia}

Como se planteó previamente, una de las dimensiones de la política pública es la jurídica, y esto implica que no solo se eviten acciones que van por fuera de los marcos legislativos avalados, sino que se responda a solicitudes expresas realizadas por la ley al ejecutivo del Estado. Un ejemplo de ello es lo indicado como esperado para la infancia colombiana por el Código de la Infancia y la Adolescencia, Ley 1098 de 2006, en el que se establece qué debe entenderse por políticas públicas de infancia y adolescencia, los principios rectores que deben guiar al Estado para garantizar la protección integral de sus derechos, y establece los responsables en el ámbito nacional, departamental y municipal, de movilizar las políticas de infancia y adolescencia en el país (Ver primer capítulo del tercer libro de la Ley).

Aun cuando el marco normativo para niñez y adolescencia en Colombia indica que las políticas públicas deben darse en coherencia con un enfoque de derechos y territorial, la tradición y las dinámicas propias de la política social en el país no lo han favorecido, revistiendo gran complejidad por la necesidad de implementar acciones integrales y articuladas a partir de sistemas fragmentados, inequitativos y sectorizados.

El país ha avanzado en documentos que presentan cada vez con mayor claridad las intenciones y orientaciones sobre la infancia, facilitando con ello la comprensión de complejidad y hasta cierto punto las tensiones y contradicciones a las que se enfrenta la puesta en marcha de acciones integrales, situadas y respetuosas con la diversidad. $\mathrm{Su}$ formulación puede detectarse en múltiples instrumentos de carácter oficial y, en otros casos, a partir de análisis derivados de las prácticas que se generan en di- 
ferentes niveles del territorio nacional, de allí la necesidad de contar con lecturas comprensivas, no lineales y abiertas a la complejidad de un mundo que no cuenta con únicas miradas y órdenes preestablecidos.

A pesar de rastrearse acciones institucionales intencionadas para la primera infancia en el país desde hace por lo menos 70 años, es desde la primera década del siglo XXI en la que se empiezan a gestar iniciativas para primera infancia de corte integral e interinstitucional; sin duda, estas propuestas han debido sortear dificultades como las planteadas en el aparte anterior.

Torrado, Gaitán, Bejarano y Torrado (2017), en el texto la política pública para la primera infancia frente a la desigualdad social en Colombia, señalan que aun cuando es posible identificar como logros de política para la primera infancia los CONPES 115 de 2008 y el 123 de 2009, en los que se definieron directrices para la destinación de recursos públicos para la atención integral en los diferentes niveles de gobierno, además de brindar claridades con respecto a la responsabilidad de las autoridades en la prestación de los servicios y sentar las bases para fortalecer acciones intersectoriales, continúa siendo un reto la autonomía en el diseño de las modalidades de atención y la descentralización de los servicios, la integración de programas nacionales que se implementan a nivel local y la articulación con las iniciativas comunitarias.

Con el fin de dar respuesta a parte de los retos identificados, Colombia ha generado diversas propuestas, entre las que se encuentra la estrategia nacional de atención integral De cero a Siempre, estrategia que orientó una serie de acciones planificadas de carácter nacional y territorial, dirigidas a promover y garantizar el desarrollo infantil desde la gestación hasta los cinco años. Las bondades de estas iniciativas han sido muchas, pero quisiéramos resaltan la promulgación de la ley 1804 de 2016 (Congreso de la República de Colombia, 2016), la cual garantiza en nuestro país un piso de exigibilidad con el que antes no se contaba.

La Ley 1804 de 2016 hace explícita la necesidad de políticas que garanticen el Desarrollo Integral de la Primera Infancia en el marco de la Doctrina de la Protección Integral, el fortalecimiento del marco institucional para el reconocimiento, garantía y protección de los derechos de niños, niñas y gestantes y el restablecimiento en caso de vulneración. Precisa la ley la necesidad de un trabajo intersectorial que articule acciones intencionadas y efectivas que aseguren en cada entorno las condiciones para la promoción y potenciación del desarrollo infantil, así mismo, la necesidad de atención "prioritaria" a quienes por diversas condiciones, debido a su cultura, pertenencia étnica, contexto, condiciones, dimensiones particulares o afectaciones transitorias, puedan estar en riesgo, como es el caso que expone este libro: la población afectada por el conflicto colombiano.

Con respecto a esto, la ley explicita que para la población a ser atendida de forma prioritaria con recursos oficiales de carácter nacional o local, se concertarán los esquemas de atención de las autoridades gubernamentales del orden nacional y lo- 
cal en los escenarios del Consejo de Política Social municipal y departamental, en consonancia con el análisis de situación de derechos y de servicios consignado en la Ruta Integral de Atenciones (RIA), esperando que con ello se puedan generar esquemas específicos de atención integral.

\section{Las políticas públicas para primera infancia y el conflicto colombiano}

Como se evidenció en los capítulos previos, las dinámicas del conflicto en Colombia han generado una serie de retos particulares para la atención de niños y niñas en sus primeros años y, claro está, para las políticas que la sustentan.

Desde hace más de diez años, un estudio realizado por la Organización de Estados Iberoamericanos y Save the Children (2009), en zonas afectadas por el conflicto armado colombiano, identificó la necesidad de que a nivel de política pública: 1) se incluyera el tema de primera infancia en los debates permanentes sobre conflicto armado colombiano, visibilizando estrategias explícitas para hacer seguimiento y monitoreo a su situación, 2) se fortaleciera la capacidad de las autoridades locales y de los programas de atención a la primera infancia, principalmente en zonas especialmente afectadas por el conflicto, generando acciones específicas para atender y prever los efectos en la vida de los niños y sus familias, 3) se diseñaran e implementaran programas con aval y financiación de los niveles departamental y municipal, y 4) se cualificaran los sistemas de seguimiento, monitoreo y control de las políticas destinadas a este fin.

Con respecto a las necesidades señaladas por la Organización de Estados Iberoamericanos y Save the Children (2009), los avances que ha realizado el país tanto a nivel legislativo como ejecutivo han sido limitado; sin embargo, se reconoce que los avances en las acciones de políticas para la primera infancia y la Ley 1804, han sentado las bases para el desarrollo de propuestas claras, intencionadas y de cada vez mayor especificidad, entre las que -sin duda- se deben encontrar las de cualificación del talento humano que trabaja con primera infancia.

Con base en lo anterior, en el resto del capítulo se presenta la propuesta de competencias construidas tomando como insumo principal la información brindada por los equipos de talento humano y los expertos que participaron en esta investigación, y que, a su vez, puede sentar bases para una propuesta de cualificación del talento humano que trabaja con primera infancia en todos los niveles del sistema, en lo relacionado con políticas públicas.

\section{La políticas públicas para la primera infancia afectada por el conflicto colombiano: diálogo en tre conceptos y evidencias}

Para incluir las opiniones y vivencias de los miembros de los equipos de talento humano en la tarea de definir las competencias sobre políticas públicas se utilizó la 
metodología de estudio de casos. Haciendo uso de ella, por grupos, los participantes expusieron el curso de atención de un caso con el cual hubiesen trabajado en su institución, usando para ello la metáfora denominada río del tiempo. Por medio de esta metáfora se profundizó en las herramientas y recursos disponibles a la llegada del caso a sus manos (nacimiento del río), los obstáculos de distinto tipo que debieron sortear durante la atención de este, así como los apoyos recibidos durante la atención (curso medio y afluentes), y las trasformaciones o el impacto que tuvieron sus acciones sobre las vidas de las personas con y para las que trabajaron en ese caso (desembocadura).

Por medio de esa estrategia se propició la reflexión sobre la relación entre políticas públicas, derechos y prestación de servicios para la atención, educación y cuidado de la primera infancia, así como propuestas de mejora a la actual política. Todo esto alrededor de tres categorías que se desarrollarán a continuación:

- Concepción de política pública.

- Integralidad de las políticas públicas para la primera infancia y prestación de servicios.

- Planificación y asignación de recursos.

\section{Competencias relacionadas con la concepción de política pública}

Las políticas públicas, como se empezó a exponer al inicio del capítulo, son medios provisionales que entremezclan y expresan tanto los ideales políticos trascendentales de los derechos humanos (libertad, igualdad, solidaridad, dignidad), como las posibilidades institucionales del momento (los medios organizacionales, la cultura y las costumbres), y los intereses individuales y colectivos de los grupos sociales y étnicos. Estas políticas también son la expresión del reconocimiento previo de una problemática social que se ha transformado en un problema político, al cual se responde mediante posibles soluciones que se construyen entre tensiones e intereses sociales, económicos y políticos (Roth, 2007).

Por lo anterior, las competencias de esta dimensión se centran en la concepción de política pública, entendida como la relación que se establece entre las personas que trabajan en el ámbito de primera infancia y las políticas públicas que han sido formuladas para la población con la que trabajan. Se entiende, además, que esta concepción se compone de la interpretación propia sobre lo que es una política pública en el contexto colombiano y los conocimientos, prácticas y valores en torno a las políticas y legislación vigente para primera infancia, familia y víctimas de conflicto.

De acuerdo con lo anterior, la concepción de política pública se centra en el sujeto (nivel individual), independientemente de si es quien presta los servicios, los gestiona, los administra o los crea y no se puede atribuir a una institución (nivel institucional), a las relaciones entre instituciones (nivel interinstitucional) o a la intervención del Estado (nivel gobernanza), sino a las personas que trabajan en cada uno de estos niveles del sistema. 
En el caso de los conocimientos sobre la legislación y políticas públicas vigentes para infancia, familia y víctimas de situaciones de conflicto, decimos que este conocimiento es parte de una competencia que se moldea según el nivel; así, por ejemplo, en el nivel individual otorga a los prestadores de servicios y con otros roles dentro de la atención, cuidado y educación para la primera infancia, una mirada amplia sobre la incidencia, alcance y responsabilidad de sus acciones, mientras que en el nivel de gobernanza, tener este conocimiento permite evaluar las políticas públicas vigentes dentro de estos marcos de política y legislación y/o crear planes, programas o estrategias que sean acordes con esas disposiciones.

En consecuencia, puesto que la concepción de política pública es una forma subjetiva e interpretativa de relación con las políticas públicas, la propuesta de competencias para esta categoría se centra en el nivel individual y pretendemos incluir en él las competencias de aquellas personas que están en contacto con las políticas públicas en todas sus fases: desde la planeación hasta la ejecución y evaluación; lo que además abarca al resto de niveles del sistema competente (institucional, interinstitucional y gobernanza). No obstante, también se realizó un esquema de competencias específico para el nivel de gobernanza, puesto que es un nivel de amplio peso en la gestación de las políticas públicas y, por lo tanto, creemos que vale la pena construir unas competencias propias a ese nivel.

\section{Nivel individual}

En los escenarios de educación inicial participan varias personas que desempeñan roles distintos; algunos están relacionados con la administración de los servicios (p. ej. coordinador, auxiliar administrativo), y otros son más cercanos a la atención directa de las niñas, niños y familias (p. ej. agente educativo, auxiliar pedagógico, profesional psicosocial, profesional de la salud).

No obstante, sin importar el tipo de rol, las personas que trabajan en escenarios de educación inicial pueden ser vistos como ejecutores de política pública, pues son quienes en última instancia materializan en su quehacer las disposiciones de las políticas públicas para la primera infancia. Además, debido a su práctica directa y diaria con los niños, familias y comunidad, tienen una visión privilegiada acerca de las fortalezas, debilidades y potencialidades de las acciones de política pública diseñadas para esta población, pudiendo ser así no solamente ejecutores de la política, sino también participantes activos en su construcción o mejora, y en este sentido cobra especial importancia la manera de entender la política pública.

De acuerdo con esto, fue posible evidenciar cómo los miembros de los equipos de talento humano reconocen varios aspectos claves que definen lo que son las políticas públicas, así, por ejemplo, señalan a estas como medios o herramientas gubernamentales para dar solución a las necesidades de la población y su materialización por medio de proyectos en cabeza del Estado; además, resaltan su papel en la garantía de derechos e identifican su función en la atención de problemáticas sociales específicas. Dos testimonios que están en la línea de lo anterior son los siguientes: 
"Es un conjunto de acciones articuladas por el estado, encaminadas a intervenir una situación o problema, las cuales son implementadas mediante proyectos, teniendo en cuenta el contexto o grupo poblacional”.

"Una política pública es una garantía (para) que se cumplan los derechos que tenemos como ciudadanos en cuanto a la salud, educación, etc.”.

Así mismo, como parte de la concepción de política pública, se destaca la necesidad de conocer sobre legislación y políticas públicas vigentes para la atención de la población menor de cinco años con el fin de enmarcar sus acciones dentro de estas disposiciones, pues los mismos miembros de los equipos de talento humano consideran que tener conocimiento en esta materia constituye un marco de referencia que garantiza atenciones de calidad; de ahí su importancia de estar familiarizados con ello, tal como lo dejan ver los siguientes testimonios:

"Es necesario tener conocimientos frente al conflicto en las diferentes zonas, así como en políticas públicas, rutas de atención y de desarrollo del posconflicto”.

“Es importante para así poder ofrecer un trabajo óptimo y de calidad”.

"Importante para que podamos tener mayor capacidad de análisis ante estos casos".

"Es importante tener los conocimientos para poder dar respuesta a algún caso que llegue al CDI para ser orientado”.

"Si nosotras como agentes educativas y tenemos estos conocimientos, los podemos transmitir a las familias beneficiarias del programa”.

Según lo anterior, las competencias propuestas para el nivel individual en la categoría de concepción de política pública son las siguientes:

Tabla 4.1. Competencias relacionadas con la concepción de política públicaNivel individual.

\section{Conocimientos}

Prácticas

Valores
- Conocimiento de las políticas públicas vigentes que inciden en la atención de la primera infancia y sus características (contradictorias, no lineales e incididas por la comprensión particular de las personas).

- Conocimiento de la legislación vigente sobre infancia y familia.

- Conocimiento sobre las disposiciones de la política pública local, regional y nacional en relación con la atención de víctimas del conflicto armado
- Actuar responsable y comprometidamente en cualquiera de los escenarios de política pública en los que se enmarquen sus prácticas profesionales.

- Enmarcar sus acciones en las disposiciones de la política pública vigente.

- Hacer acompañamiento a los beneficiarios en los procesos de atención que se inician dentro de la institución $\mathrm{y}$ en otras instituciones.
- Asumir con ética las acciones y gestiones que debe realizar en la fase de política pública en que se encuentre (identificación de problemas, formulación, decisión, implementación, evaluación). 


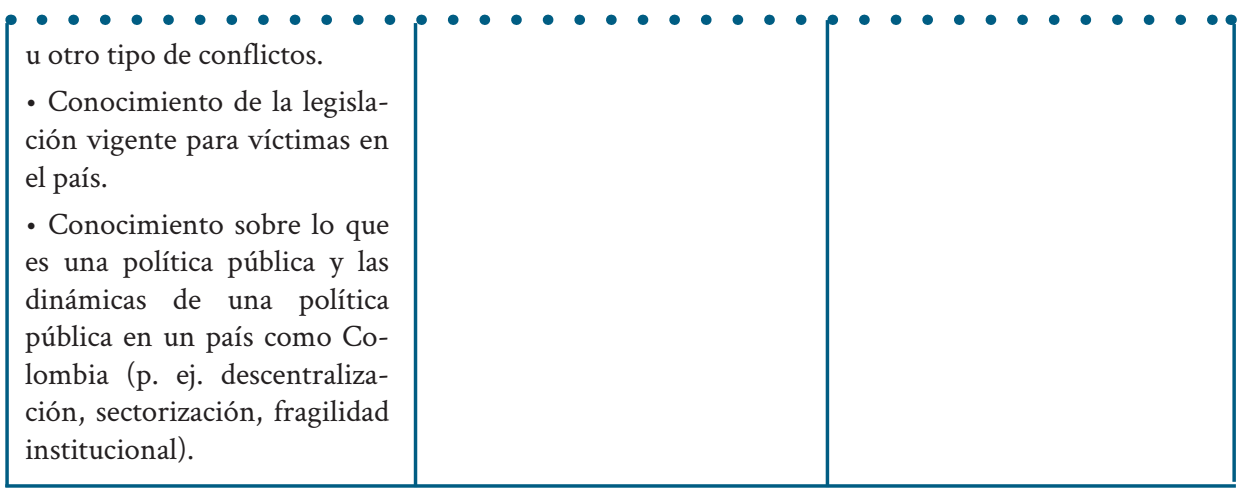

\section{Nivel de gobernanza}

Las concepciones que circulan en este nivel permiten identificar la necesidad de conocer en detalle las diferentes responsabilidades que se demarcan desde el legislativo y el ejecutivo entre el gobierno nacional, departamental y local y, además, reiteran los participantes, como ya lo han hecho otros autores (Durán y Torrado, 2017), las demandas que se tienen, sobre todo en términos prácticos, sobre la integralidad, la intersectorialidad y el trabajo interinstitucional.

También fue posible identificar una concepción arraigada frente a la forma en que se hacen las políticas nacionales, resaltando la tendencia a homogeneizar problemas y soluciones sin la consulta y participación adecuada de los territorios, lo que sin duda genera, a criterio de los participantes, soluciones ideales que demandan procesos de lucha por la creación de condiciones materiales que permitan el cumplimiento de tales ideales, lo que minimiza, o incluso lleva a la renuncia, a iniciativas locales y comunitarias que puedan tener mayor aceptación y potencial de transformación, sobre todo en temas relacionados con el conflicto colombiano.

La primera infancia vive hoy las contradicciones y tensiones naturales de establecer políticas para diferentes formas de ser, hacer y valorar en relación con los derechos de los niños, por lo tanto, hay una oportunidad latente de llevar la formulación de políticas y su implementación en el diálogo local y territorial; esto implica, necesariamente, que las políticas lleguen a ser estrategias concretas, situadas, y no descontextualizadas o con un alcance predominantemente técnico. La orientación política, que para algunos participantes es por ahora más una intención que una realidad, sobre la necesidad de acciones integrales e intersectoriales, con alianzas territoriales, abre una ventana de oportunidad, que sin duda no está exenta de debate y tensión, y para ello consideramos puede ser pertinente cualificar a los equipos frente a los siguientes conocimientos, prácticas y valores.

Con base en lo anterior, las competencias propuestas para el nivel de gobernanza en cuanto a concepción de política pública son las siguientes: 
Tabla 4.2. Competencias relacionadas con la concepción de política pública - Nivel de gobernanza.

\begin{tabular}{|c|c|c|}
\hline Conocimientos & Prácticas & Valores \\
\hline $\begin{array}{l}\text { - Conocimiento de la legisla- } \\
\text { ción vigente sobre infancia y } \\
\text { familia. } \\
\text { - Conocimiento de la legisla- } \\
\text { ción vigente para víctimas en } \\
\text { el país. } \\
\text { - Conocimientos sobre la si- } \\
\text { tuación de garantía de dere- } \\
\text { chos de población infantil y el } \\
\text { estado de la prestación de ser- } \\
\text { vicios para la garantía de sus } \\
\text { derechos. } \\
\text { - Conocimientos sobre la si- } \\
\text { tuación de garantía y repara- } \\
\text { ción de derechos de población } \\
\text { víctima del conflicto. } \\
\text { - Conocimiento de las acciones } \\
\text { que se puede gestionar en el } \\
\text { marco de las políticas públicas } \\
\text { vigentes y aquellas que se de- } \\
\text { ben gestionar. } \\
\text { - Conocimientos del Estado, el } \\
\text { Gobierno y de administración } \\
\text { pública. } \\
\text { - Conocimientos sobre inci- } \\
\text { dencia política - advocacy. }\end{array}$ & $\begin{array}{l}\text { - Identificar necesidades social- } \\
\text { mente relevantes de la primera } \\
\text { infancia y población víctima de } \\
\text { conflictos que ameriten accio- } \\
\text { nes de política pública. } \\
\text { - "Construir" problemas que } \\
\text { afecten a la garantía de los de- } \\
\text { rechos de la primera infancia y } \\
\text { población víctima de conflictos, } \\
\text { que sean susceptibles de poner- } \\
\text { se en agenda para debates de } \\
\text { política pública. } \\
\text { - Analizar roles y responsa- } \\
\text { bilidades institucionales para } \\
\text { promover acciones integrales y } \\
\text { viables de implementación para } \\
\text { la garantía de los derechos de la } \\
\text { primera infancia y la población } \\
\text { víctima de conflictos. } \\
\text { - Evaluar las propuestas que } \\
\text { son susceptibles de convertirse } \\
\text { en acciones de política pública } \\
\text { para la primera infancia o po- } \\
\text { blación víctima de conflictos. }\end{array}$ & $\begin{array}{l}\text { - Velar por políticas de pri- } \\
\text { mera infancia y población } \\
\text { víctima de conflictos que res- } \\
\text { pondan coherentemente a los } \\
\text { postulados de la Constitución } \\
\text { Política de Colombia (Estado } \\
\text { Democrático, descentralizado } \\
\text { y Social de Derecho). }\end{array}$ \\
\hline
\end{tabular}

\section{La integralidad de las políticas públicas para la primera infan- cia y la prestación de servicios}

La integralidad puede ser entendida como una característica deseable de las políticas públicas para la primera infancia, pues tiene que ver con la capacidad de las mismas para garantizar la realización de todos los derechos de los niños y niñas entre los 0 y 5 años. Implica que la realización plena de un derecho dependa de la realización de los demás derechos, la adopción de medidas de protección integral para ellos y la prestación de servicios integrales durante la atención (Durán, 2017).

Esta concepción integral de las políticas públicas es contraria a la arquitectura institucional sectorial que caracteriza nuestro país para la garantía de derechos, puesto que propende por la integración de sectores, agentes, planes y programas en torno a un objetivo común (Molina, Torres y Moromizato, 2013), y de base adopta un enfoque de derechos, ya que concibe la atención a la primera infancia como un asunto de inclusión social y equidad, y no desde la postura de contención social o caridad (Durán, 2017). 
En el país, la actual Política de Estado para el Desarrollo Integral de la Primera Infancia de Cero a Siempre es quizás la apuesta más grande que se ha hecho en los últimos años en materia de atención a esta población, y fue construida bajo esta concepción de integralidad (Congreso de la República de Colombia, 2016). Con este panorama como antesala, a continuación se analiza por nivel el conjunto de competencias propuesto que está relacionado con la integralidad de las políticas públicas para la primera infancia y la prestación de servicios.

\section{Nivel individual}

Derivados de los testimonios de los participantes de la investigación, en el nivel individual las competencias propuestas se construyeron en torno a tres aspectos centrales que tienen que ver con la realización de prácticas conjuntas entre los miembros del equipo de atención de la institución según las necesidades de los niños, niñas y familias, la actuación en el marco de rutas de atención establecidas y la gestión activa de los miembros del equipo ante dificultades en el proceso de atención.

Sobre el primer aspecto, los participantes señalan que su trabajo se enmarca en acciones interdisciplinarias, es decir, que la atención no se realiza de forma aislada, sino contando con el apoyo del resto del equipo de acuerdo con las particularidades de cada caso. Así, las experiencias relatadas indican que el proceso de atención de (o para) las madres gestantes, madres, niños y niñas implica la participación de un equipo pedagógico, un equipo psicosocial y un equipo nutricional como realizadores principales de la atención. De esta manera, las maestras y auxiliares pedagógicas llevan a cabo visitas familiares y sesiones educativas grupales en las que se abordan temas relacionados con el cuidado, la crianza y el desarrollo infantil. Los profesionales de apoyo psicosocial brindan orientación, especialmente a las madres, y el equipo de nutrición y de salud vela por el adecuado estado nutricional y físico de madres gestantes, niñas y niños.

Acerca del segundo aspecto, este se refiere a la activación de rutas de atención tendientes a la gestión de servicios a cargo de otras instituciones. Esta activación consiste en la derivación de los usuarios a estos servicios, e incluye el seguimiento al proceso que cada uno lleva dentro de ellos. Algunas de las rutas mencionadas fueron las siguientes: ruta para trámite de documentos de identificación, ruta para la atención de casos de violencia intrafamiliar, ruta para el acceso a servicios de salud y ruta para el direccionamiento de servicios de salud.

Por su parte, en el tercer aspecto, varias experiencias relatadas indican que los miembros del equipo de atención no únicamente activan las rutas de atención, sino que realizan acompañamiento de los casos y gestión con funcionarios de otras instituciones para lograr el acceso efectivo de los usuarios a los servicios que requieren en el momento, es decir, se propende por una atención oportuna.

De esta manera, se considera que las competencias que deben promoverse con el talento humano en este nivel son las siguientes: 
Tabla 4.3. Competencias relacionadas con la integralidad de las politicas públicas para la primera infancia y la prestación de servicios - Nivel individual.

\begin{tabular}{|c|c|c|}
\hline Conocimientos & Prácticas & Valores \\
\hline $\begin{array}{l}\text { - Conocimiento de los ser- } \\
\text { vicios a los que pueden acce- } \\
\text { der los usuarios dentro de su } \\
\text { institución y en otras insti- } \\
\text { tuciones afines, así como los } \\
\text { medios para acceder a todos } \\
\text { estos servicios. } \\
\text { - Conocimiento sobre los } \\
\text { roles y responsabilidades de } \\
\text { cada uno de los actores y los } \\
\text { procesos de direccionamien- } \\
\text { to a otras modalidades de su } \\
\text { institución y en otras institu- } \\
\text { ciones para complementar la } \\
\text { atención. } \\
\text { - Conocimiento de las rutas } \\
\text { establecidas para la atención } \\
\text { integral, la manera de acti- } \\
\text { varlas y los procesos que se } \\
\text { deben seguir. }\end{array}$ & $\begin{array}{l}\text { - Prestar los servicios corres- } \\
\text { pondientes a su rol, teniendo } \\
\text { en cuenta las particularidades } \\
\text { de cada caso (p. ej. necesidades, } \\
\text { fortalezas, debilidades, recur- } \\
\text { sos disponibles). } \\
\text { - Resolver los problemas que } \\
\text { surgen durante la prestación } \\
\text { del servicio y la gestión inte- } \\
\text { rinstitucional que entorpecen } \\
\text { la garantía de derechos de ni- } \\
\text { ños, niñas y familias. } \\
\text { - Acordar planes interdiscipli- } \\
\text { narios con los otros miembros } \\
\text { del equipo de atención (maes- } \\
\text { tra, auxiliar pedagógica, profe- } \\
\text { sional psicosocial, profesional } \\
\text { de la salud), en los que se defi- } \\
\text { na el papel de cada uno ante un } \\
\text { caso en cuestión. } \\
\text { - Prestar los servicios corres- } \\
\text { pondientes a su rol, teniendo } \\
\text { en cuenta los objetivos globa- } \\
\text { les de atención definidos por el } \\
\text { equipo interdisciplinario. } \\
\text { - Activar, gestionar, mejorar } \\
\text { y/o participar en la construc- } \\
\text { ción de rutas (en caso que no } \\
\text { existan) que favorezcan el ac- } \\
\text { ceso de los beneficiarios a los } \\
\text { servicios que se requieran con } \\
\text { otras instituciones (p. ej. a tra- } \\
\text { vés de la ruta adecuada, en los } \\
\text { tiempos y bajo los criterios de } \\
\text { la institución a la que se le de- } \\
\text { manda el servicio). }\end{array}$ & $\begin{array}{l}\text { - Comprometerse con la } \\
\text { prestación de servicios opor- } \\
\text { tunos que sean ofertados, } \\
\text { teniendo en cuenta las parti- } \\
\text { cularidades de cada caso (cul- } \\
\text { tura de servicio). } \\
\text { - Fomentar el trabajo colabo- } \\
\text { rativo interdisciplinar en el } \\
\text { manejo de los casos durante } \\
\text { el proceso de atención. } \\
\text { - Buscar siempre la interac- } \\
\text { ción adecuada entre los ser- } \\
\text { vicios prestados por las dis- } \\
\text { tintas instituciones. }\end{array}$ \\
\hline
\end{tabular}

\section{Nivel institucional}

En este nivel se identificó, además de la necesidad de habilidades de gestión interinstitucional, el papel de las instituciones en la priorización de acciones para poblaciones en condiciones de vulnerabilidad, así como en el fomento de la corresponsabilidad en la garantía de derechos de los niños, niñas y familias.

En este sentido, los aportes de los participantes que orientaron las competencias 
configuradas para este nivel, en cuanto a integralidad de las políticas públicas para la primera infancia y la prestación de servicios, resaltan la necesidad de que las instituciones a las que pertenecen los equipos de atención mantengan y establezcan alianzas con otras instituciones que les permitan dar un mayor alcance a sus prácticas.

“(...) que se evidenciaran más las instituciones, que nos dieran a conocer qué otras redes de apoyo dentro de la localidad y pues fuera de la localidad como para también orientar esas familias".

Por otro lado, otros aportes que aplican para el nivel institucional del sistema indican la importancia de concientizar a las familias de su papel activo en la garantía de los derechos de los niños desde el abordaje del núcleo familiar o de cuidado.

“(...) porque ¿qué es lo que busca nuestro programa? fortalecer a las familias, brindarles herramientas para que sean ellas mismas quienes a partir de las herramientas que nosotros les brindamos, ellas sean quienes solucionen sus conflictos y sean capaces de salir adelante por sí solas, eso es lo que buscamos como modalidad".

"Lo que decíamos acá, este programa debería medirse por una superación de necesidades, porque también entramos a una zona de confort de que "allá me dan entonces tengo 1, 2, 3 y voy y los vinculo y son desplazados", que hay una zona de confort donde yo ya tengo la posibilidad, tengo conocimiento previo, sé las rutas de atención, sé por dónde generar ingresos dentro de mi familia, es cómo la superación de necesidades nos hace cambiar esa mentalidad jsí? Si yo ya tengo un ingreso, ya tengo un trabajo "démosle la oportunidad a otra persona que en realidad está empezando y lo necesita”, pero a veces vemos a mamás que tienen un bebé, luego tienen otro bebé... Ahorita no tenemos niños de dos años, entonces papás furiosos "que vamos a demandar, que ICBF nos está quitando los derechos", pero también es cómo hacerle entender a la familia que su niño ya terminó un proceso en este medio familiar y necesita otro proceso".

"(Un obstáculo para la atención) es la falta de voluntad, no todas (las madres) tienen disposición con ciertas cosas: compromiso. Puede que la mamá lo necesite mucho, pero si ya es falta de voluntad, ya sea madrugar para recibir la sesión o recibirnos en el encuentro familiar, eso sería un obstáculo".

De igual forma, se identificó un rol crucial de las instituciones en la priorización de servicios para los participantes que se enfrentan a vulneración de derechos o están en riesgo de ello. Un ejemplo recurrente fue la priorización de la atención para migrantes venezolanos y de niños y niñas expuestos a situaciones de riesgo como el maltrato intrafamiliar. Situaciones que configuran un foco de conflictos distinto al de las situaciones propias del conflicto armado y que ahora parecen ser más frecuentes en los escenarios de educación inicial, según los relatos de los participantes. Algunos de los testimonios que reflejan estas situaciones son los siguientes:

"Priorizar la legalización de documentos (de identificación), priorizando la atención de la salud, porque ahí sí es bastante demorado el proceso de esta ruta, donde Planeación (Distrital) les hace una visita, luego viene el cargue del puntaje, después la legalización del puntaje para adquirir un servicio de salud totalmente gratuito de parte del Estado (...) porque un niño con riesgo de desnutrición que le salga la salud en 3, 4 meses, no, por eso pasan casos terribles en los que se mueren los niños por falta de atención (...) y más cuando estamos hablando de ser garantes de los derechos de la primera infancia”.

"A veces hay, como son personas desplazadas que vienen de otro lado, problema para que les activen acá (en Bogotá) la salud, no hay esa prioridad que tanto dicen para mujeres embaraza- 
das o niños menores, no la hay, el proceso es muy demorado".

“(...) cuando se ve la vulneración de derechos, principalmente cuando son los niños ahí sí se activa la ruta, o sea se hace un denuncio anónimo o se hace un llamado de atención a la familia, digamos acá también el psicólogo tiene el tiempo de escucha, que digamos no solo se activan las rutas para maltrato, sino hay diferentes situaciones en las que se pueden activar las rutas (...) igual cuando hay vulneración de derechos, cuando el niño no tiene EPS, que no hayan controles de crecimiento y desarrollo, (...) cuando no lo registran rápido, todo ese tipo, es más que todo cuando hay vulneración de derechos que se activan las rutas de atención (...) Las nutricionistas también hacen un reporte a ICBF y a la EPS cuando el niño está en desnutrición".

Tomando en cuenta lo anterior, para este nivel las competencias que deben promoverse son:

Tabla 4.4. Competencias relacionadas con la integralidad de las politicas públicas para la primera infancia y la prestación de servicios - Nivel institucional.

Conocimientos

- Conocimiento de las acciones que se puede gestionar en el marco de las políticas públicas vigentes y aquellas que se deben gestionar.

- Conocimiento de las instituciones que hacen parte de la red de atención integral, sus roles y responsabilidades (por ley, por política pública).

- Conocimiento de los servicios que oferta cada institución y las rutas de acceso a los mismos, para toda la población y los que se ofertan de manera exclusiva para población en situación de vulnerabilidad.

- Conocimiento de los principios de garantía y corresponsabilidad del enfoque de Derechos.
- Priorizar acciones pertinentes para la atención de población en condiciones de vulnerabilidad y víctimas de conflictos.

- Incorporar instrumentos de caracterización de los niños y sus familias en lo relacionado con el nivel de afectación que han tenido a raíz del conflicto armado u otro tipo de conflictos para brindarles atención diferencial.

- Dar solución oportuna a problemas derivados de la atención dentro de la propia institución y aquellos inherentes a la gestión interinstitucional.

- Garantizar el cumplimiento de las acciones estipuladas por ley y las políticas públicas, asegurando la prestación de los servicios, la infraestructura, el personal y recursos necesarios para responder de manera coherente con dichos compromisos.

- Incorporar estrategias tendientes a concientizar a las familias sobre su rol ac-
- Adoptar un enfoque integral de atención que incluya acciones sobre los niños, sus padres, cuidadores y/o acudientes (cuando sea necesario), con el fin de asegurar condiciones óptimas de desarrollo del niño por medio del bienestar de todo su núcleo familiar o de cuidado.

- Comprender que uno de los fines de la atención integral es promover la garantía plena de derechos de la primera infancia por parte del Estado y la corresponsabilidad de las partes, entre ellas la familia o cuidadores.

- Velar por que los participantes de los servicios comprendan sus derechos y los mecanismos de garantía y exigibilidad. 


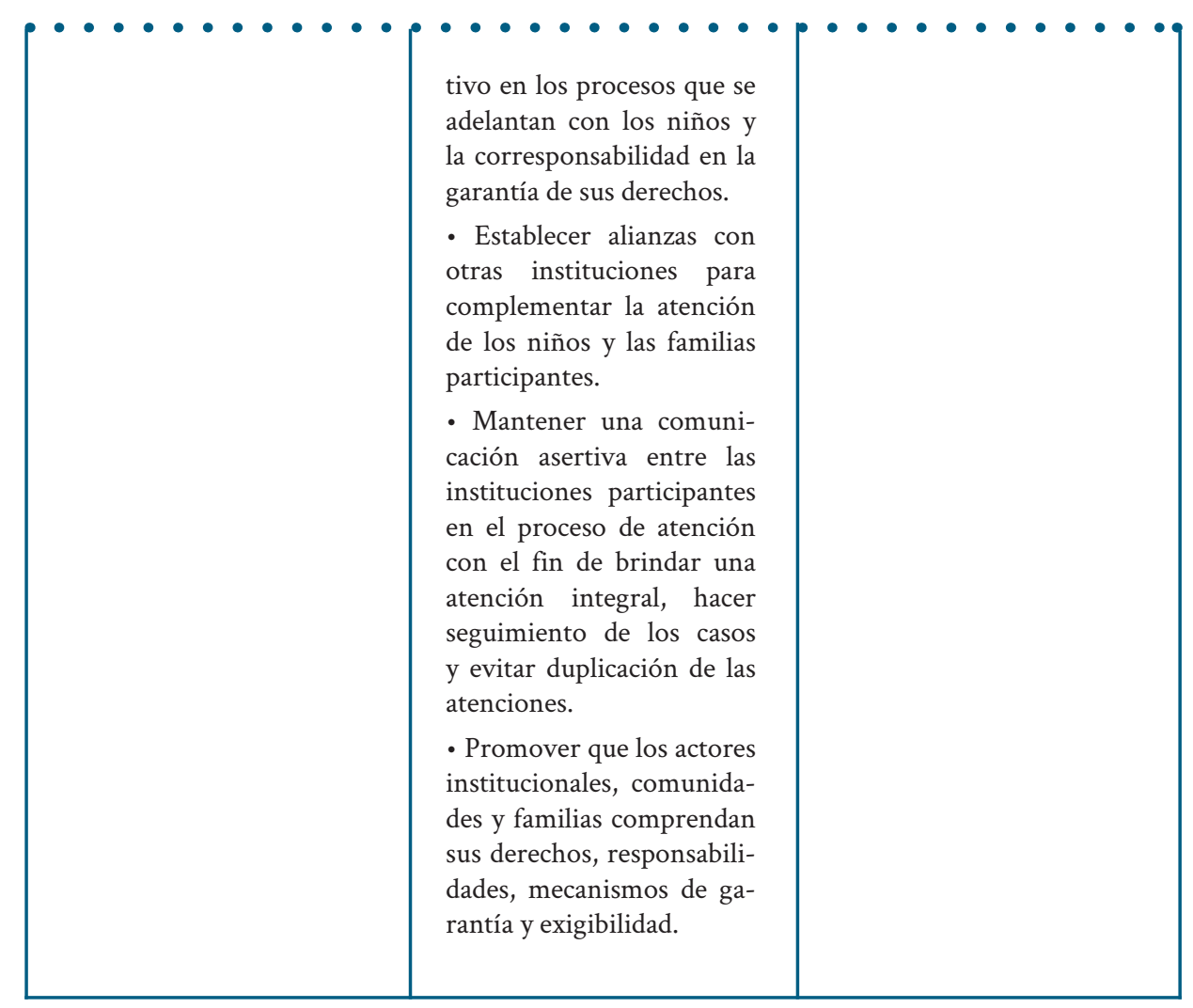

\section{Nivel interinstitucional}

En el ámbito interinstitucional se identificaron competencias relacionadas con el funcionamiento en red del conjunto de instituciones que tienen responsabilidad directa en el trabajo con la primera infancia: entidades de salud, educación, recreación y cultura, principalmente, y también las competencias que permiten la integración de sectores para alcanzar objetivos compartidos.

De este nivel se destacan las competencias relacionadas con la coordinación de acciones en las que participan estas entidades/instituciones de distintos sectores y que tienen que ver con la gestión y trabajo cooperativo entre ellas. Este trabajo cooperativo y no competitivo se prioriza en las relaciones interinstitucionales, puesto que asegura, entre otras cosas, la toma de liderazgo y trabajo mancomunado en temas relevantes para más de una entidad/institución, la optimización de los procesos de focalización de la atención y la no duplicación de acciones o servicios similares en la población (Durán, 2017).

Las competencias construidas para este nivel en relación con integralidad de las políticas públicas y prestación de servicios son las siguientes. 
Tabla 4.5. Competencias relacionadas con la integralidad de las políticas públicas para la primera infancia y la prestación de servicios - Nivel interinstitucional.

\begin{tabular}{|c|c|c|}
\hline Conocimientos & Prácticas & Valores \\
\hline $\begin{array}{l}\text { - Conocimiento sobre cómo } \\
\text { realizar gestión interinstitu- } \\
\text { cional y planes de acción para } \\
\text { la promoción de la primera } \\
\text { infancia. } \\
\text { - Conocimiento sobre nego- } \\
\text { ciación y manejo de conflic- } \\
\text { tos que puedan suscitarse por } \\
\text { las dinámicas institucionales. } \\
\text { - Conocimientos del Estado, } \\
\text { el gobierno y de administra- } \\
\text { ción pública. }\end{array}$ & $\begin{array}{l}\text { - Disponer ámbitos o escena- } \\
\text { rios que favorezcan el diálogo } \\
\text { y la puesta en marcha de ac- } \\
\text { ciones interinstitucionales (p. } \\
\text { ej. alianzas del tercer sector, } \\
\text { CPS, mesas intersectoriales). } \\
\text { - Atender con prontitud, y de } \\
\text { manera sistémica, a las difi- } \\
\text { cultades que se presentan en } \\
\text { la atención integral por fallos } \\
\text { propios de los esquemas de } \\
\text { atención sectorial y la foca- } \\
\text { lización para el acceso a los } \\
\text { recursos. } \\
\text { - Resolver los problemas de } \\
\text { manera estructural, haciendo } \\
\text { las gestiones que sean nece- } \\
\text { sarias para movilizar recursos } \\
\text { que desbordan la capacidad } \\
\text { institucional } \\
\text { - Priorizar acciones perti- } \\
\text { nentes para la atención de } \\
\text { población en condiciones de } \\
\text { vulnerabilidad y víctimas de } \\
\text { conflictos. }\end{array}$ & $\begin{array}{l}\text { - Garantizar la resolución de } \\
\text { problemas derivados de las } \\
\text { lógicas sectoriales ante las de- } \\
\text { mandas de atención integral } \\
\text { que requiere la población in- } \\
\text { fantil, sus familias y las vícti- } \\
\text { mas de conflictos. }\end{array}$ \\
\hline
\end{tabular}

\section{Nivel gobernanza}

Las competencias de este nivel están estrechamente relacionadas con las funciones estipuladas para los distintos sectores que integran la Comisión Intersectorial de Primera Infancia (CIPI; Departamento Administrativo de la Presidencia de la República, 2011) en relación con la implementación, monitoreo y evaluación de las acciones de política pública para esta población.

No obstante, se intentó rescatar, en clave de competencias (conocimientos, prácticas y valores), las percepciones de los miembros de los equipos de talento humano participantes en la investigación.

De este modo, se destaca la opinión bastante recurrente acerca de las estrategias de seguimiento a los programas que actualmente realizan las entidades a cargo, pues muchas de las personas entrevistadas tienen la percepción de que los formatos administrativos por medio de los que se hace control y seguimiento afectan la calidad de la labor de servicio con los usuarios, puesto que restan tiempo efectivo de atención 
con los niños, niñas y familias y promueven una lógica cuantitativa que sesga los resultados de impacto y calidad de los programas a los datos numéricos de cobertura.

De ahí que se sugiriera, entre otras competencias, para el nivel de gobernanza lo siguiente: optimizar los recursos de seguimiento y evaluación para minimizar la sobrecarga administrativa para los agentes educativos, así como la integralidad de actores/prácticas (cualitativas/cuantitativas) y concepciones de la calidad de los programas en aras de la garantía de los derechos de la población infantil, y aquella que ha sido víctima del conflicto.

Algunos de los aportes de los participantes que están en la línea de lo anterior son los siguientes:

"una falencia que se ve es que hay mucha papelería, el trabajo se evalúa en papelería y a veces por hacer papelería de pronto uno tiene las ideas, pero no se pueden ejecutar porque no queda tiempo, entonces aquí no hay esa presencia de ver qué se está haciendo sino solo con papel y eso es lo que da cuenta del trabajo, entonces un cambio que nosotros opinamos sería eso, como cambiar los métodos de auditoría, de revisión, para llevar mejor las acciones, tener más acciones porque a veces no queda el tiempo, es solo escribir, escribir, escribir, entonces es como eso, nos evalúan es con la cantidad de papeles que entregamos".

"Yo digo que nosotros, las entidades, perpetuamos el asistencialismo con la burocracia, cuando a uno le piden pasar un informe o lo que sea, primero es la cantidad y después la calidad, el problema es que al sistema le importa más la burocracia que la calidad y eso lo lleva a uno corriendo, porque si usted sabe que usted tiene qué hacer, tiene el taller regio, pero tiene que hacer tanto, tanto, tanto ¿qué escoge? Así somos todos por el sistema y creo que es la primera falla, por eso perpetuamos el asistencialismo, porque vienen las mamás y uno es: no se les olvide firmar, la firma, la firma; es así".

De esta manera, el esquema de competencias en esta categoría para el nivel de gobernanza es el que se presenta enseguida.

Tabla 4.6. Competencias relacionadas con la integralidad de las politicas públicas para la primera infancia y la prestación de servicios - Nivel de gobernanza.

\begin{tabular}{|c|c|c|}
\hline Conocimientos & Prácticas & Valores \\
\hline $\begin{array}{l}\text { - Conocimiento de los prin- } \\
\text { cipios de garantía y corres- } \\
\text { ponsabilidad del enfoque de } \\
\text { derechos. } \\
\text { - Conocimiento de los roles y } \\
\text { responsabilidad de cada nivel } \\
\text { de gobierno. } \\
\text { - Conocimiento de los instru- } \\
\text { mentos de evaluación, moni- } \\
\text { toreo y seguimiento que debe } \\
\text { realizar el nivel nacional para } \\
\text { verificación de cumplimiento } \\
\text { de ley y políticas. }\end{array}$ & $\begin{array}{l}\text { - Formular acciones de go- } \\
\text { bierno que, sin dejar de lado la } \\
\text { garantía de los derechos de la } \\
\text { población infantil en general, } \\
\text { y aquella que ha sido víctima } \\
\text { de conflictos, promuevan la } \\
\text { corresponsabilidad de familias, } \\
\text { cuidadores y comunidad. } \\
\text { - Verificar la inclusión de los } \\
\text { temas de infancia y población } \\
\text { víctima del conflicto en los di- } \\
\text { ferentes instrumentos de polí- } \\
\text { tica en el nivel departamental, }\end{array}$ & $\begin{array}{l}\text { - Fomentar la corresponsabili- } \\
\text { dad de la garantía de los dere- } \\
\text { chos de los niños, con enfoque } \\
\text { diferencial. } \\
\text { - Exigir que los gobiernos } \\
\text { locales implementan las ac- } \\
\text { ciones que se exigen para in- } \\
\text { fancia y población víctima del } \\
\text { conflicto. } \\
\text { - Adoptar una visión sistémica } \\
\text { (multifactorial) de la calidad } \\
\text { de los programas en aras de la } \\
\text { garantía de los derechos de la }\end{array}$ \\
\hline
\end{tabular}




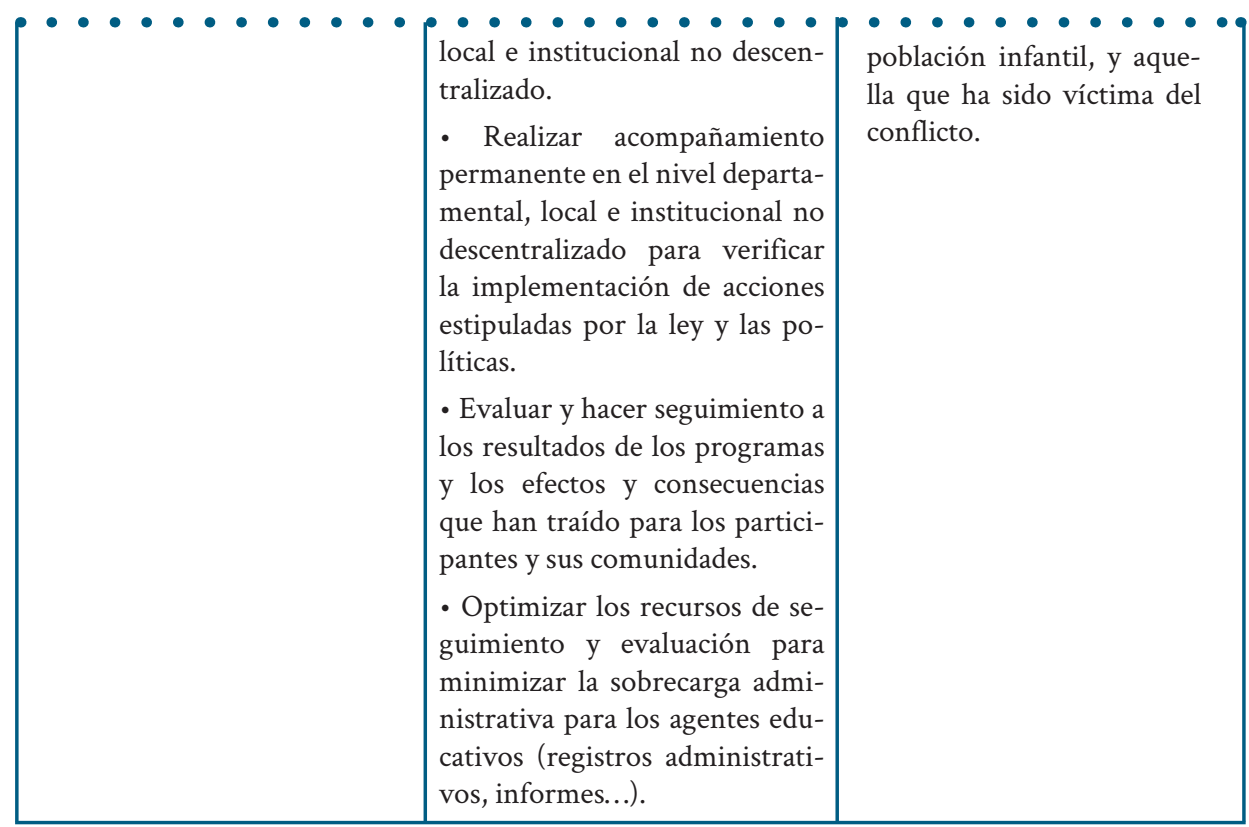

\section{La planeación de políticas y asignación de recursos}

Con respecto a esta categoría, es importante señalar lo expuesto por UNICEF (2018), frente a los presupuestos para la niñez. Indica la agencia que la Convención sobre los Derechos del Niño en su artículo 4 explicita que, para dar cumplimiento efectivo a los derechos, los Estados deben ejecutar todas las medidas administrativas y legislativas necesarias, adoptando medidas hasta el máximo de los recursos de que dispongan; y agrega en la Observación General $N^{\circ} 19$, que esto implica un cambio en la forma en que dichos Estados planifican, ejecutan y supervisan los presupuestos a favor de este grupo poblacional. En Colombia muchos son los retos, no solo por la ampliación y sostenibilidad de partidas presupuestales para la infancia, sino también por el monitoreo y seguimiento que se hace a las ya destinadas, combatiendo de manera contundente la corrupción y malversación de recursos.

Tal como se presentó al comienzo del texto, la Ley 1804 señala que el Gobierno nacional debe proyectar y garantizar los recursos para la implementación de la política para la Primera Infancia, con base en las metas de cobertura y gestión que se definan en el marco de la Comisión Intersectorial para la Atención Integral de la Primera Infancia, además del presupuesto que deben destinar para este fin las entidades del orden nacional y territorial para la atención integral. Exige la ley que se deben reglamentar los esquemas de financiación y cofinanciación entre la Nación y el territorio, además de una gestión intencionada de fuentes financieras complementarias a los recursos de la Nación.

Señala Garnier (2000), que el presupuesto es una herramienta fundamental para que el gobierno destine los recursos necesarios para poner en marcha los compromisos 
derivados de las políticas públicas, y para esto se hace indispensable articular procesos de planificación y lecturas detalladas de presupuesto.

Comprender un presupuesto es de vital importancia, ya que permite identificar las prioridades de política y cómo el gobierno redistribuye los recursos que toma de la sociedad. Ahora, no es solo saber leer presupuestos y conocer la forma en que se estructuran, es conocer los mecanismos a partir de los cuales se organizó la planificación que le sustentan, cómo se definieron los montos y su destinación y cómo hacer ajustes en caso de que los mismos no se adecuen consistentemente a las necesidades identificadas en los territorios e instituciones.

La construcción de un presupuesto conlleva a un proceso de alta complejidad, ya que implica contar con conocimiento amplio de los recursos con los que se cuenta, que vale la pena aclarar, no solo son económicos, sino, además, los compromisos legales y de política que de base ya puedan tener estos recursos, así como las distintas necesidades y expectativas que las instituciones y beneficiarios tengan con dichos recursos. En palabras de Aguilar (2006) implica entonces tener en consideración las dimensiones jurídicas, economía, organizacional y política de las políticas públicas.

Hablar de presupuesto lleva al concepto de planeación, que al menos desde la lógica con la que se planifica en Colombia, es entendido como un proceso racional que exige decidir cómo, con qué y con quién hacer frente a una situación o problemática, teniendo que elegir entre múltiples opciones aquellas que sean compatibles con los medios disponibles.

Siguiendo a Roth (2018), la planeación viene de una tradición racional que gira en torno a los mecanismos para tomar decisiones eficientes y eficaces, reduciendo al máximo la incertidumbre. Sin duda, no es la única manera de planear, pero esta es la opción con la que actualmente trabajan la mayoría de los Estados, incluido Colombia, y que resulta de alta relevancia para la comprensión de cómo activar un sistema de atención competente con base en las estructuras de acción del Estado que lo contiene. A pesar de dificultades como la incapacidad de integrar nuevos elementos, la planificación también goza de bondades como su apoyo en la toma de decisiones; la reducción de la incertidumbre puede minimizar la incoherencia en la acción pública, favorece la identificación de contradicciones, ayuda a cotejar la capacidad real y presupuestal frente a las múltiples demandas, aumenta la capacidad de prospección y hace transparente el proceso de seguimiento de la acción estatal a partir de la generación de información, sistemas e indicadores.

Para que un sistema de atención a la primera infancia sea competente es indispensable que en sus distintos niveles se puedan garantizar conocimientos, prácticas y valores frente a la planeación, así como en el presupuesto, sobre todo por la complejidad del trabajo con población afectada por distintos tipos de conflicto, entre ellos el armado.

Una parte importante de las dificultades con las que se enfrente la política de pri- 
mera infancia se debe a estos temas, de allí la urgencia de reflexionar sobre las necesidades de cualificación de talento humano en los diferentes niveles del sistema. A continuación, presentamos la propuesta construida con base en los aportes brindados por los integrantes de los equipos de talento humano frente a las necesidades de conocimientos, prácticas y valores en torno a la categoría de planeación y asignación de recursos.

\section{Nivel individual}

A partir del trabajo con los equipos de talento humano, pero también con los expertos que acompañaron el proceso de validación de las competencias, pudimos identificar que aun cuando los equipos del talento humano conocen las necesidades de la población con la que trabajan y son conscientes de las dificultades con las que se pueden encontrar al trabajar con ellos con la calidad requerida, por falta de recursos, algunos de ellos económicos, no era del todo claro para los equipos cómo se pueden gestionar nuevos recursos institucionales, gubernamentales, privados o incluso internacionales. En otras palabras, es claro que los recursos son escasos para las necesidades identificadas con la población atendida, pero no se cuenta en todas las instancias con los conocimientos ni prácticas para conseguir nuevos recursos, hacer lecturas amplias para identificar en dónde pueden estar los cuellos de botella para hacer las solicitudes de reasignaciones presupuestales y ajustes a las actividades que las sustentan, o las herramientas de incidencia para solicitar ajustes reales en la planeación o el presupuesto.

Si bien es claro que a nivel individual son distintos los roles y responsabilidades que tienen los diferentes integrantes de los equipos del talento humano, en términos generales todos podrían desarrollar competencias que les permitan hacer lecturas comprensivas de los recursos con los que se cuentan, los criterios con los que se distribuyen frente a las necesidades identificadas, los compromisos a los que pueden estar atados parte de dichos recursos y las formas con los que se podrían activar o liberar los recursos humanos, comunitarios, financieros o físicos con los que se cuenta o los que se puede contar. Más abajo, algunos testimonios de los participantes que apoyan lo anterior:

\footnotetext{
"Hace poquito abrieron los jardines y se ven perjudicados una cantidad de niños y es por eso, ¿por qué no está el presupuesto?”.

"Hay un momento donde dicen que es sostenible, eso es también lo que hay que mirar, de pronto estos programas así del Estado, ellos tienen que tener un presupuesto, yo me imagino que ellos ya deben tener el presupuesto para el próximo año. Y algo que no pasa por ejemplo a nivel distrital, por ejemplo, los de Integración, que ellos cuando se acaba el presupuesto pues tienen que parar todo, paran jardines, cierran jardines porque no hay la nueva contratación o el nuevo presupuesto, entonces acá habla que tienen que ser sostenibles".
}

Consideramos, entonces, que las competencias que pueden trabajarse en los esquemas de cualificación del talento humano a nivel individual sobre presupuestos son: 
Tabla 4.7. Competencias relacionadas con la planeación de políticas y asignación de recursosNivel individual.

\begin{tabular}{|c|c|c|}
\hline Conocimientos & Prácticas & Valores \\
\hline $\begin{array}{l}\text { Conocimientos básicos } \\
\text { para la construcción de pre- } \\
\text { supuestos participativos que } \\
\text { respondan a las necesidades e } \\
\text { intereses de las comunidades y } \\
\text { los territorios, específicamen- } \\
\text { te aquellos vinculados con el } \\
\text { conflicto colombiano. } \\
\text { - Conocimientos sobre los } \\
\text { recursos destinados directa } \\
\text { e indirectamente a primera } \\
\text { infancia y conflicto en el or- } \\
\text { den territorial, institucional, } \\
\text { familiar y comunitario, sus } \\
\text { condiciones y mecanismos de } \\
\text { obtención. }\end{array}$ & $\begin{array}{l}\text { - Discutir sobre las necesidades } \\
\text { propias de la comunidad en la } \\
\text { que se trabaja (y que están li- } \\
\text { gadas con la prestación de los } \\
\text { servicios propios de su rol), en } \\
\text { los espacios gubernamentales } \\
\text { y comunitarios diseñados para } \\
\text { tal fin. } \\
\text { - Participar activamente y con } \\
\text { criterio en los espacios insti- } \\
\text { tucionales de construcción de } \\
\text { presupuesto, toma de decisio- } \\
\text { nes acerca de la distribución, } \\
\text { manejo de los recursos en la } \\
\text { institución u organización a la } \\
\text { que pertenece y en los esque- } \\
\text { mas de veeduría-auditoría, se- } \\
\text { gún corresponda. }\end{array}$ & $\begin{array}{l}\text { - Darle importancia a su rol en } \\
\text { la gestión de transformación } \\
\text { social dentro de la comunidad } \\
\text { en la que trabaja. }\end{array}$ \\
\hline
\end{tabular}

\section{Nivel institucional e interinstitucional}

Si bien son niveles distintos, a continuación se presentan articuladamente los conocimientos, prácticas y valores con los que debe contar el sistema de atención a la primera infancia para garantizar los recursos apropiados para la efectiva consecución de las metas propuestas. Es claro que aun cuando cada institución tiene unas metas particulares a la luz de sus roles y responsabilidades, la atención integral para la primera infancia requiere de acciones conjuntas frente a objetivos compartidos que exigen un mayor diálogo y disposición de las instituciones para actuar en conjunto; así, sin perder la especificidad es indispensable aunar esfuerzos, recursos y gestiones, más aún por la complejidad en la atención de población víctima del conflicto colombiano.

Es importante aclarar que si estos niveles no generan las condiciones para una planeación y asignación de recursos acorde con las necesidades de la población con la que trabajan, será muy difícil que desde el nivel individual los equipos del talento humano puedan resolver las dificultades identificadas; es decir, la acción individual está sujeta a las ampliaciones que se logren desde el nivel institucional e interinstitucional dada su capacidad de incidencia en instancias en las que se toman decisiones de alcance nacional y territorial. Ahora bien, estos niveles, sin duda, podrán tomar mejores decisiones que acompañan la comprensión de las dinámicas institucionales por parte de sus equipos, pues son ellos quienes tienen contacto directo con la 
población y viven en carne propia las dificultades inherentes de la implementación de la política, generando para ello espacios de participación para conocer sus necesidades, pero sobre todo sus propuestas. Los siguientes testimonios dejan ver la importancia de lo anterior.

"Nota de campo. Al preguntarles a las agentes (que presentaron el caso de la ruta nutricional en el CDI modalidad familiar), qué proponen, estas señalaron con énfasis la necesidad de mejorar los presupuestos de todos los servicios de atención a la primera infancia. Establecen las agentes que la dificultad es no contar con un presupuesto suficiente para atender y ayudar a todas las familias, pero especialmente a aquellas que no logran ser priorizadas".

"Y pues lo que nosotros cambiaríamos en la política pública es, de pronto, más inversión, porque, digamos, sí vemos que nos exigen cierta cualificación, cierto grado de estudio y los sueldos no, no pagan bien. Entonces sí exigen ciertas competencias o ciertos perfiles, pues así mismo deberían invertir en ellos".

De acuerdo con lo expuesto, las competencias para los niveles institucional e interinstitucional en la categoría de planeación y asignación de recursos serían las desarrolladas en la siguiente tabla.

Tabla 4.8. Competencias relacionadas con la planeación de políticas y asignación de recursos - Nivel institucional e interinstitucional.

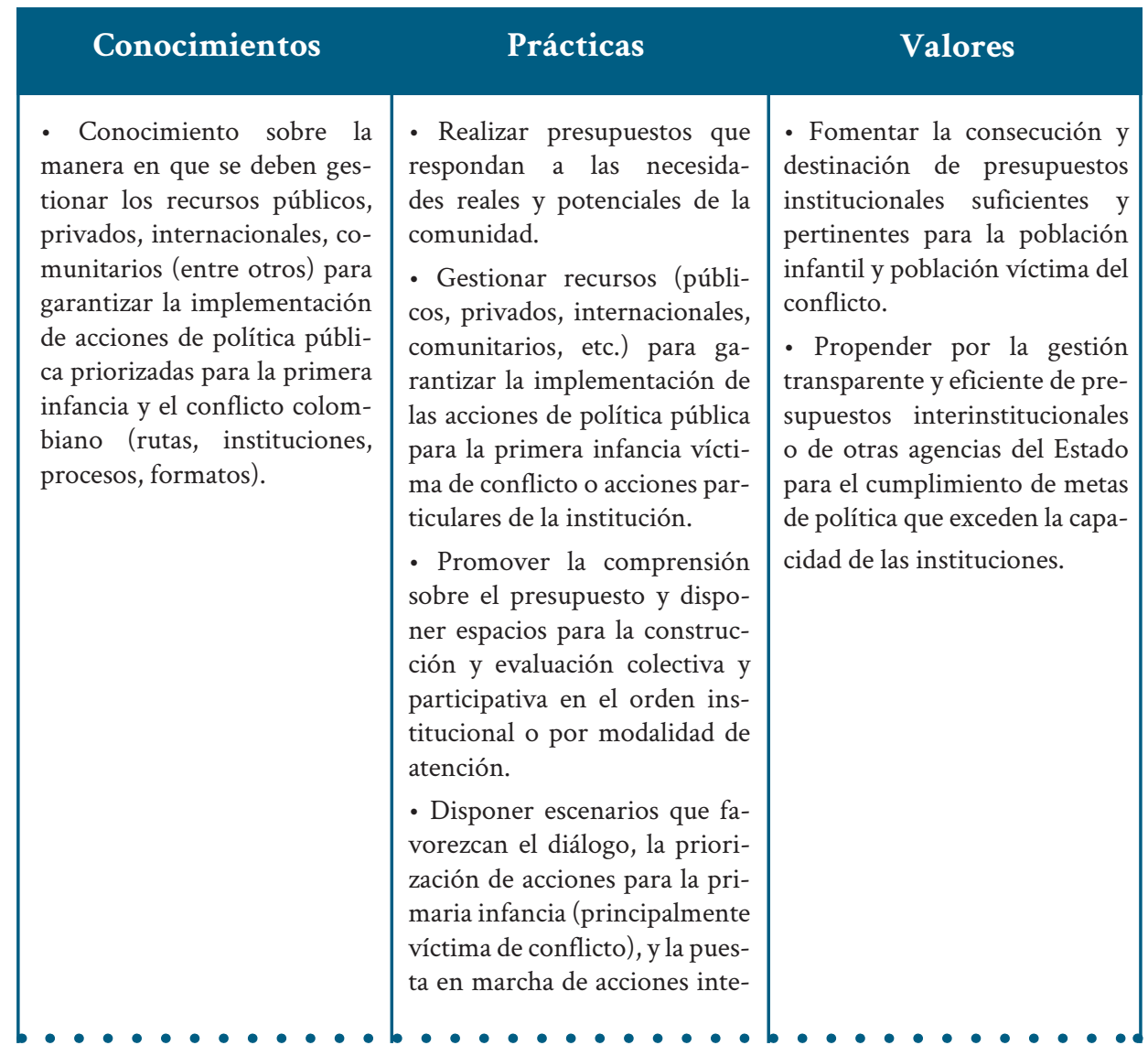




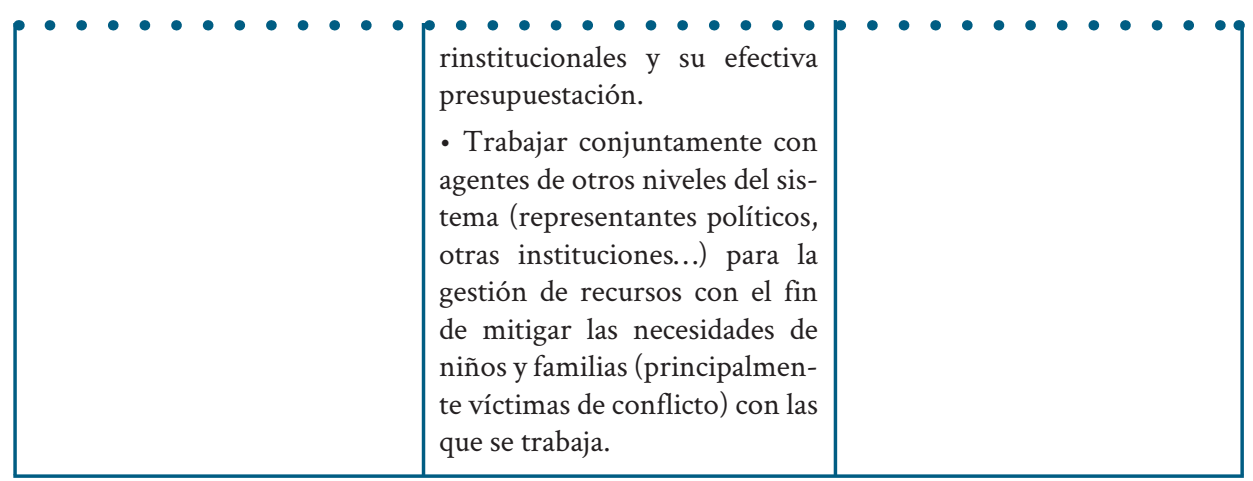

\section{Nivel de gobernanza}

Este nivel es de vital importancia dado el nivel de impacto que puede tener en las condiciones que dificultan que el sistema sea realmente competente. A partir del diálogo con los equipos de talento humano y con los expertos del orden nacional se pueden identificar los conocimientos, prácticas y valores que se necesitan desde el nivel que genera los encuadres sobre los que se ponen en marcha las políticas y acciones para la primera infancia.

La voluntad política, la claridad frente a los compromisos adquiridos, el diálogo efectivo entre los diferentes niveles territoriales y con autonomía en la gestión, así como la generación de mecanismos de monitoreo y seguimiento fueron aspectos señalados en las mesas de trabajo para la inclusión en el esquema de competencias que se presenta enseguida para el nivel de gobernanza en relación con la planeación y asignación de recursos.

Tabla 4.9. Competencias relacionadas con la planeación de politicas y asignación de recursosNivel de gobernanza.

\section{Conocimientos}

- Conocimientos sobre seguimiento, monitoreo y evaluación de los recursos destinados a primera infancia y conflicto, así como su incidencia e impacto en las condiciones de vida de los niños y sus familias.

- Conocimiento sobre la manera de hacer auditoría y veeduría, con alta incidencia de la sociedad y las comunidades, a los recursos destinados y asignados a primera infancia y

\section{Prácticas}

Valores

- Priorizar, y blindar, recursos de orden nacional, departamental y local para población en condición de vulnerabilidad y víctimas de conflictos para los problemas identificados.

- Garantizar la inclusión del tema de primeria infancia y víctimas en los Planes de Desarrollo (según nivel territorial), partidas presupuestales $\mathrm{y}$ esquemas de monitoreo y seguimiento explícitos.

- Explicitar las formas en que
- Garantizar presupuestos (en los diferentes niveles territoriales) para el cumplimiento de metas de política que exceden la capacidad de las instituciones.

- Visibilizar los recursos culturales, comunitarios y familiares y valorarlos como activos de importancia en la construcción de presupuestos para la población infantil y víctima del conflicto. 


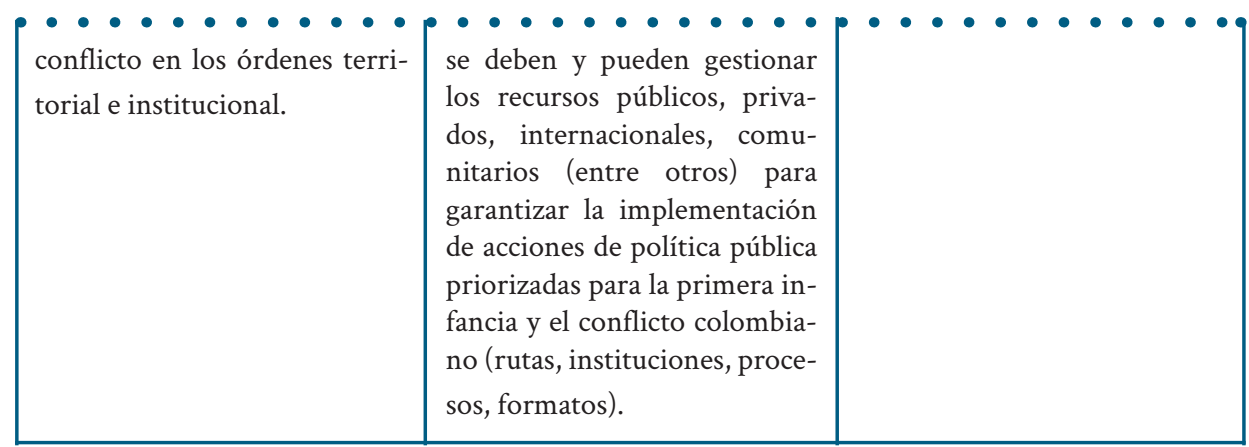

\section{Conclusiones}

La primera infancia es un tema relevante de política pública en el país; a lo largo de los años se han ido adoptando enfoques o concepciones distintas acerca de las niñas y niños, sus derechos y su protección, lo que ha ido moldeando estas políticas y las acciones derivadas de ellas. Una de estas concepciones es la de integralidad de los niños como sujetos y de sus derechos, y es el enfoque con el que actualmente se quiere sustentar todas las acciones de política pública para la primera infancia en Colombia.

Aunque como consecuencia de lo anterior se han definido unas bases sobre las cuales diseñar e implementar acciones de política pública para la población menor de 5 años, lo que se valora como un gran avance, varios autores y los participantes de esta investigación coinciden en que aún son muchos los retos por afrontar, principalmente aquellos que tienen que ver con cómo trabajar con y por la primera infancia, principalmente aquella que ha sido víctima del conflicto colombiano, de forma articulada, integral e intersectorial en una estructura institucional que no lo facilita y a la que le cuesta la puesta en marcha de acciones que logren poner en diálogo las necesidades de la nación y las propias de los territorios y las comunidades.

Como aporte para hacer frente a estos retos se propuso un esquema de competencias que recoge la voz de distintos actores que trabajan en varios ámbitos de la educación inicial y atención para la primera infancia. Tales competencias se estructuraron en torno a la concepción de política pública, prestación de servicios, planeación y asignación de recursos, y por medio de ellas se quiso visibilizar el papel de los actores de cada nivel del sistema.

Se apuesta a que este esquema de competencias sirva para hacer frente a aquellas situaciones que imponen las dinámicas derivadas del conflicto colombiano, un reto más para las políticas de primera infancia, tal como lo reveló hace algunos años un estudio en zonas afectadas por el conflicto, hecho por la Organización de Estados Iberoamericanos y Save de Children (2009), en el que se observaron falencias en la gestión de recursos y puesta en marcha de iniciativas propias en esos territorios.

De esta manera, se quiso exponer en este capítulo las competencias (conocimientos, 
prácticas y valores), que a la luz de los hallazgos del estudio que se presenta en todo el libro, permitan analizar necesidades locales, identificar soluciones, poner sobre la mesa temas relacionados con la primera infancia, gestionar recursos y mantener las estrategias diseñadas o proponer mejoras a las existentes, especialmente cuando se trata de mejorar los servicios y acciones que se llevan a cabo con la primera infancia afectada por el conflicto colombiano.

Entendemos que esta tarea no es algo que se logre en solitario, y por eso se especifican competencias en cada nivel del sistema, resaltando especialmente aquellas del nivel individual, pues a veces el asunto de políticas públicas tiende a verse como algo alejado de lo personal, como un asunto que le compete más al Estado.

\section{Referencias}

Aguilar, L. (2006). Aspectos centrales de una política pública. Memorias del Segundo Foro Internacional Movilización por la Primera Infancia. Bogotá, Colombia.

Aguilar, L. (2012). Política pública: una visión panorámica. La Paz, Bolivia: Programa de Naciones Unidas para el Desarrollo. Recuperado de: https://cutt.ly/ee8CMre

Congreso de la República de Colombia. (2016). Ley 1804 de 2016. Por la cual se establece la política de Estado para el desarrollo integral de la primera infancia de cero a siempre y se dictan otras disposiciones. Bogotá, Colombia: Congreso de la República de Colombia.

Departamento Administrativo de la Presidencia de la República. (2011). Decreto 4875 de 2011. Por el cual se crea la Comisión Intersectorial para la Atención Integral de la Primera Infancia -AIPI- y la Comisión Especial de Seguimiento para la Atención Integral a la Primera Infancia. Bogotá, Colombia: Departamento Administrativo de la Presidencia de la República.

Departamento Nacional de Planeación, Ministerio de Educación Nacional, Ministerio de Protección Social, Instituto Colombiano de Bienestar Familiar. (2007). Marco para las Políticas Públicas y Lineamientos para la Planeación del Desarrollo de la Infancia y la Adolescencia en el Municipio -Guía para Alcaldes-. Bogotá, Colombia: Departamento Nacional de Planeación. Recuperado de: https://cutt.ly/2e8VQ2d

Durán, E. (2017). Integralidad y políticas locales de infancia y adolescencia. En E. Durán y M. Torrado (Eds.). (2017). Políticas de infancia y adolescencia ¿Camino a la equidad? (221-252). Bogotá, Colombia: Colección Centro de Estudios Sociales -CES-, Universidad Nacional de Colombia.

Durán, E, y Torrado, M. (Eds.). (2017). Políticas públicas de infancia y adolescencia ¿Camino a la equidad? Bogotá, Colombia: Colección Centro de Estudios Sociales -CES-, Universidad Nacional de Colombia.

Garnier, L. (2000). Función de coordinación de planes y políticas. Santiago de Chile, Chile: Instituto Latinoamericano y del Caribe de Planificación Económica y Social, ILPES. Recuperado de: https://cutt.ly/ze8B43H

Meny, I., y Thoenig, J. (1992). Las políticas públicas. Barcelona, España: Ariel.

Molina, H., Torres, A., y Moromizato, R. (2013). Áreas críticas para la gestión de políticas integrales de desarrollo infantil. Banco Interamericano de Desarrollo. Recuperado de: https://cutt.ly/ je8BGHc

Organización de Estados Iberoamericanos y Save the Children. (2009). Colombia: huellas del conflicto en la primera infancia. Bogotá, Colombia. Recuperado de: https://cutt.ly/pe8Vkkz

Roth, A. (2007). Enfoques y teorías para el análisis de políticas públicas, cambio de la acción pública y transformaciones del Estado. En: J. Jolly y J. Cuervo (Eds.), Ensayos sobre políticas públicas. Bogotá, Colombia: Universidad Externado de Colombia. 
Roth, A. (2018). Políticas públicas: formulación, implementación y evaluación. Bogotá, Colombia: Ediciones Aurora.

Suárez, F. (1989). Problemas sociales y problemas de programas sociales masivos. Santiago de Chile, Chile: Comisión Económica para América Latina y el Caribe. Recuperado de: https://cutt. ly/De8VwLB

Torrado, M., Gaitán, M., Bejarano, D., y Torrado, M. (2017). La política pública para la primera infancia frente a la desigualdad social en Colombia. En: E. Durán y M. Pacheco (Eds.), Políticas de infancia y adolescencia ¿Camino a la equidad? Bogotá, Colombia: Colección Centro de Estudios Sociales -CES-, Universidad Nacional de Colombia.

UNICEF. (2018). Presupuesto para la niñez. Recuperado de: https://cutt.ly/ae8B0bu 


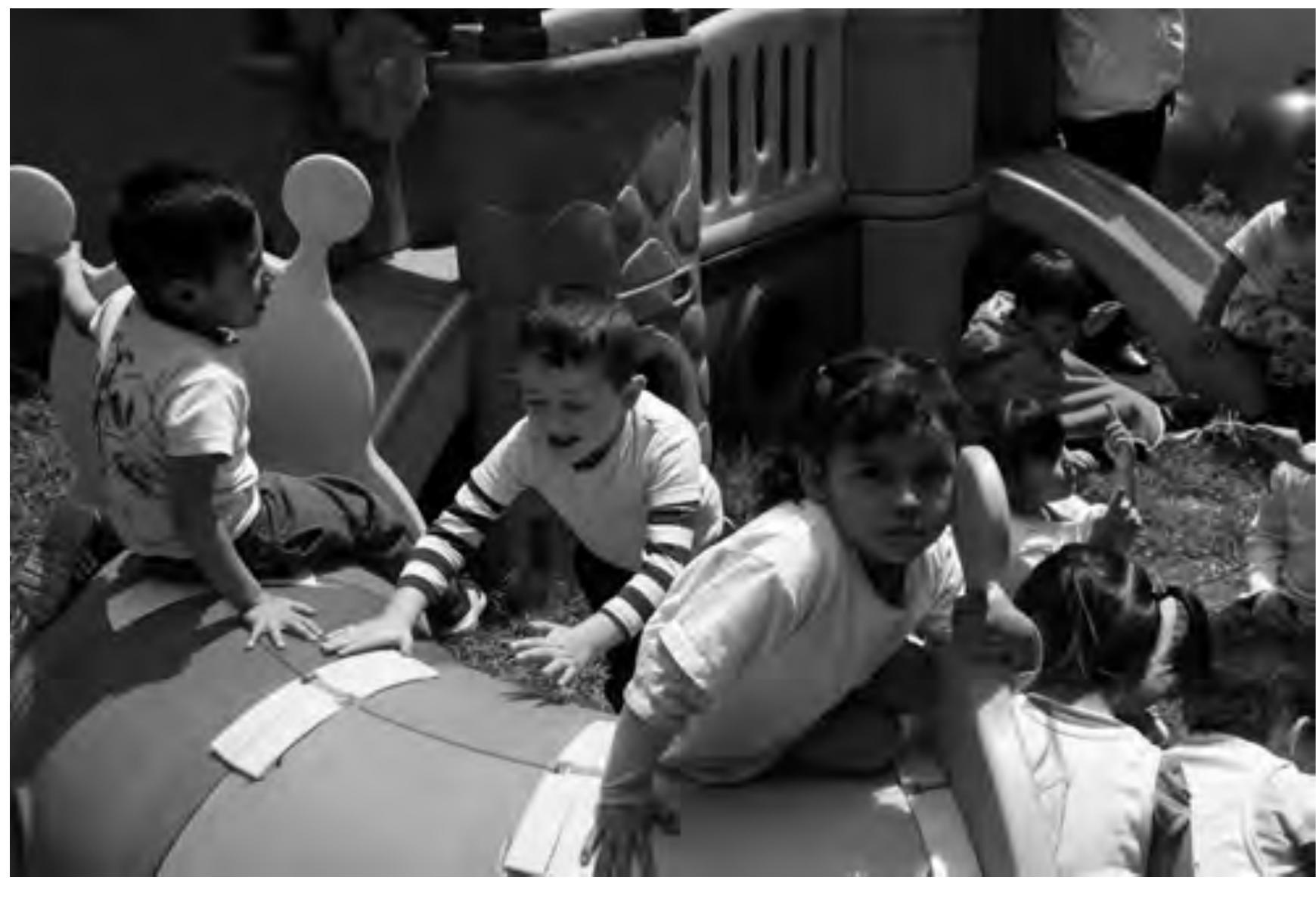

